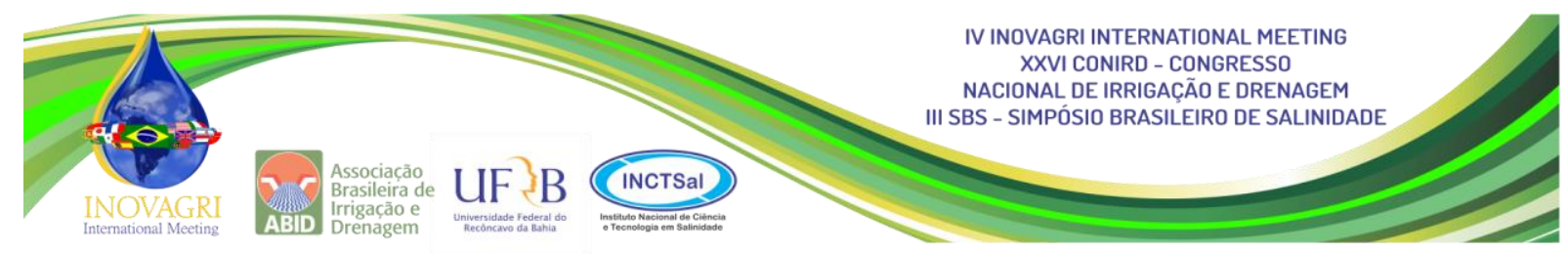

\title{
POTENCIAL PRODUTIVO DE LINHAGENS DE FEIJOEIRO-COMUM PARA O SUBMÉDIO DO VALE DO SÃO FRANCISCO
}

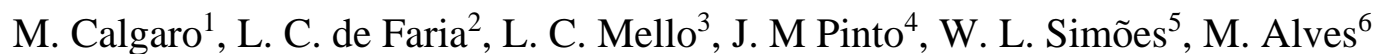

RESUMO: O presente trabalho teve como objetivo avaliar o potencial produtivo de linhagens de feijoeiro-comum do tipo carioca de ciclo precoce para o submédio do Vale do São Francisco. Para tanto, o delineamento experimental utilizado foi o de blocos casualizados, onde cada unidade experimental constitui-se de três repetições, com parcelas de quatro linhas com quatro metros de comprimento. $\mathrm{O}$ experimento foi irrigado com base na $\mathrm{ET}_{0}$ determinada por meio de uma estação agrometeorológica instalada próxima a área experimental e o sistema utilizado foi o gotejamento superficial, com uma linha de gotejadores para cada duas linhas de plantio e emissores espaçados entre si em 0,5 m. As avaliações realizadas durante o estudo foram da produção e a produtividade média de grãos, determinadas em kg.ha- ${ }^{1}$. As produtividades obtidas na área experimental, demonstram que dentre os 12 materiais avaliados, 9 apresentam potencial produtivo elevado, com produtividades médias de 2.584,25 kg.ha- ${ }^{1}$.

PALAVRAS-CHAVE: Phaseolus vulgaris, feijão carioca, melhoramento.

\section{PRODUCTIVE POTENTIAL OF COMMON BEAN LINES FOR THE SUB MIDLEI OF THE SÃO FRANCISCO VALLEY}

SUMMARY: The present work had as objective to evaluate the productive potential of common bean lineages of the Carioca type of early cycle for the submedia of the São Francisco Valley. For this, the experimental design was a randomized block design, where each experimental unit consisted of three replicates, with four-line plots with four meters in length. The experiment was irrigated based on $\mathrm{ET}_{0}$ determined by means of an agrometeorological station installed near the experimental area and the system used was surface dripping with one line of drippers for each two planting lines and emitters spaced

\footnotetext{
${ }^{1}$ Doutor, Pesquisador da Embrapa Semiárido, Petrolina - Pernambuco. Email: marcelo.calgaro@embrapa.br

${ }^{2}$ Doutor, Pesquisador da Embrapa Arroz e Feijão, Santo Antônio de Jesus - Goias. Email: luis.faria@embrapa.br

${ }^{3}$ Doutor, Pesquisador da Embrapa Arroz e Feijão, Santo Antônio de Jesus - Goias. Email: leonardo.mello@embrapa.br

${ }^{4}$ Doutor, Pesquisador da Embrapa Semiárido, Petrolina - Pernambuco. Email: jose-maria.pinto@embrapa.br

${ }^{5}$ Doutor, Pesquisador da Embrapa Semiárido, Petrolina - Pernambuco. Email: welson.simoes@embrapa.br

${ }^{6}$ Bolsista, Acadêmico de Ciências Biológicas da UPE, Petrolina - Pernambuco. Email: manoelalves2013@hotmail.com
} 
apart by $0.5 \mathrm{~m}$. The evaluations carried out during the study were of the production and average yield of grains, determined in $\mathrm{kg} \cdot \mathrm{ha}^{-1}$. The yields obtained in the experimental area show that among the 12 evaluated materials, 9 have high productive potential, with average yields of $2,584.25 \mathrm{~kg} \cdot \mathrm{ha}^{-1}$.

KEYWORDS: Phaseolus vulgaris, carioca bean, improvement.

\section{INTRODUÇÃO}

A capacidade de produzir em áreas com restrições aos fatores de produção como clima, solo, relevo entre outros, diferencia os materiais de melhor desempenho em cada região produtora. No Nordeste brasileiro, os principais fatores restritivos a produção do feijãocomum, são a temperaturas altas, que provocam o abortamento floral e a precipitação insuficiente ou ausente, tornando por vezes o cultivo inviável (Silva \& Wander, 2013).

A produtividade média da cultura do feijão-comum no nordeste brasileiro gira em torno de $518 \mathrm{~kg} \cdot \mathrm{ha}^{-1}$, com forte influência dos fatores climáticos. Para diminuir ou eliminar um desses fatores, uma das opções é fazer uso de técnicas de irrigação no período onde a precipitação é escassa e a temperatura seja amena na época da floração. Sendo assim, a irrigação localizada apresenta-se com um dos métodos apropriados ao cultivo de subsistência do feijoeiro-comum (Barbosa \& Gonzaga, 2012).

Pensando em adaptar materiais que possam ser produzidos nessas condições, um estudo realizado pela Embrapa Arroz e Feijão e a Embrapa Semiárido, vem sendo desenvolvido no sentido de melhorar geneticamente, por meio de seleção recorrente, genótipos de feijãocomum do tipo precoce.

Assim, o objetivo deste trabalho foi avaliar o potencial produtivo de linhagens de feijãocomum para o submédio do Vale do São Francisco.

\section{MATERIAL E MÉTODOS}

O trabalho foi desenvolvido no Perímetro Irrigado de Bebedouro, localizado no Município de Petrolina, PE, (latitude: 9 $9^{\circ} 09^{\prime}$ S, longitude: $40^{\circ} 22^{\prime} \mathrm{W}$, altitude: $365,5 \mathrm{~m}$ ), onde a Embrapa Semiárido possui um Campo Experimental. O solo do local é classificado como Latossolo vermelho amarelo distrófico (EMBRAPA, 2006). As precipitações concentram-se entre novembro e abril, e tem como principal característica serem irregularmente distribuídas, 
com média anual em torno de $426 \mathrm{~mm}$ (EMBRAPA, 2016). A classificação climática, segundo Köppen (1918) é do tipo BSWh, ou seja, tropical semiárido, conforme descrito em Reddy \& Amorim Neto (1983). A temperatura média anual é de $28,3^{\circ} \mathrm{C}$, com variação entre 21 e $32^{\circ} \mathrm{C}$, com uma evaporação média anual em torno de $2000 \mathrm{~mm}$, umidade relativa do ar média anual de 68,5. Apresenta ainda velocidade média do vento de 2,3 m.s $\mathrm{s}^{-1}$ e 3000 horas anuais de brilho solar (EMBRAPA, 2016).

Para a realização dessa pesquisa foram semeadas 12 linhagens de feijão-comum de ciclo precoce, sendo elas CNFC 15856, CNFC 16242, CNFC 16729, CNFC 15723, CNFC 16066, CNFC 16871, CNFC 16831, CNFC 16832, CNFC 16188, CNFC 16846, CNFC 16820 e CNFC 15708 e uma cultivar testemunha (BRS NOTÁVEL), distribuídos em blocos inteiramente casualizados, com três repetições, em parcelas de 4 fileiras com 4 metros de comprimento, espaçadas $0,3 \mathrm{~m}$ entre fileiras. A adubação foi realizada conforme recomendação técnica para o cultivo na região, com aplicação de $20 \mathrm{~kg} \cdot \mathrm{ha}^{-1}$ de N, $20 \mathrm{~kg} \cdot \mathrm{ha}^{-1}$ de $\mathrm{P}_{2} \mathrm{O}_{5}$ e $20 \mathrm{~kg} \cdot \mathrm{ha}^{-1}$ de $\mathrm{K}_{2} \mathrm{O}$. A adubação de cobertura foi aplicada $40 \mathrm{~kg}$.ha-1 de $\mathrm{N}$, aos 20 dias após a emergência. Os tratos culturais realizados foram os recomendados para a cultura do feijoeiro (Araújo et al., 1996).

A semeadura foi realizada no dia 22 de junho de 2016, sendo necessário o uso de um sistema de irrigação para proporcionar pleno desenvolvimento a cultura. O método de irrigação utilizado foi a localizada, com gotejadores superficiais espaçados $0,5 \mathrm{~m}$ entre si e vazão média de 2,0 L.h ${ }^{-1}$. O manejo da irrigação foi realizado elevando a umidade do solo até a capacidade de campo logo após o termino da semeadura e posteriormente as irrigações foram realizadas visando repor a quantidade de água evapotranspirada pela cultura, com base na evapotranspiração de referência determinada por meio de uma estação agrometeorológica instalada próxima a área experimental (Allen et al., 1998), e do coeficiente de cultivo (kc), sugeridos por Silveira \& Stone (2016) para cada fase da cultura, conforme apresentados na Tabela 1. A uniformidade de distribuição do sistema de irrigação foi de $96 \%$, tendo sida determinada a campo conforme metodologia proposta por Keller \& Karmeli (1975). O turno de rega adotado foi de dois dias.

Para as análises propostas neste trabalho, foram colhidas, no momento da maturação completa, as duas fileiras centrais de 4 metros de comprimento, equivalente a 2,4 $\mathrm{m}^{2}$, sendo determinadas as produtividades médias por hectare dos genótipos e o percentual de redução de produtividade em relação a testemunha. As médias foram comparadas pelo teste de ScottKnott a $5 \%$ de probabilidade. 


\section{RESULTADOS E DISCUSSÃO}

Os valores de produtividade média apresentados na Tabela 2, permitem visualizar o bom desempenho dos genótipos testados. Observou-se que o genótipo CNFC 15856 apresentou em valores absolutos uma produtividade de $2.996,32 \mathrm{~kg} \cdot \mathrm{ha}^{-1}$.

Se levada em consideração a produtividade média do feijão-comum para a região Nordeste, que é de $559 \mathrm{~kg} \cdot \mathrm{ha}^{-1}$, segundo Silva \& Wander (2013), podemos perceber que os diversos materiais testados apresentam ótimo potencial para produção no Semiárido nordestino. Destaca-se nesse conjunto ainda a linhagem CNFC 16242 que produziu 2.717,89 kg.ha-1 ${ }^{-1}$ com redução de 9,90\% em relação a testemunha. A ocorrência de produtividades superiores as encontradas para a região nordeste e para o submédio do Vale do São Francisco como as ocorridas neste estudo podem estar atreladas ao uso da irrigação e da adubação adequada. Outro fator que determina a obtenção de produtividades elevadas segundo Barbosa \& Gonzaga (2012), é uma equilibrada população de plantas. Os autores ainda citam que a cultura tem potencial para atingir produtividades em torno de $4.000 \mathrm{~kg} \cdot \mathrm{ha}^{-1}$. Nesse ciclo de produção foram fornecidos as plantas 440,95 mm de água via irrigação, não ocorrendo no mesmo período nenhum evento de precipitação.

Dos 12 materiais avaliados, apenas 3 diferiram estatisticamente da testemunha, evidenciando o ótimo potencial de linhagens passiveis de serem utilizadas futuramente na produção de feijão-comum no Nordeste brasileiro. Apenas a linhagem CNFC 15708 apresentou uma produtividade abaixo de $2.000,00 \mathrm{~kg} \cdot \mathrm{ha}^{-1}$ e redução de 42,35\% em relação a testemunha, ficando, porém, conforme citado anteriormente, acima da média para a região Nordeste e para o submédio do Vale do São Francisco, segundo Costa \& Lopes (1999).

\section{CONCLUSÕES}

As linhagens CNFC 15856, CNFC 16242, CNFC 16729, CNFC 15723, CNFC 16066, CNFC 16871, CNFC 16831, CNFC 16832 e CNFC 16188 apresentaram potencial produtivo para a produção no submédio do Vale do São Francisco.

\section{AGRADECIMENTOS}

Nosso agradecimento especial aos funcionários do Campo Experimental de Bebedouro, aos bolsistas e estagiários que se empenharam na condução do experimento. 


\section{REFERÊNCIAS BIBLIOGRÁFICAS}

ALLEN, R. G.; PEREIRA, L. S.; RAES, D.; SMITH, M. Crop evapotranspiration: Guidelines for computing crop water requirements. Rome: FAO, 1998. 300 p. (FAO - Irrigation and Drainage Paper, 56).

ARAÚJO, Ricardo S.; RAVA, Carlos A.; STONE, Luis F.; ZIMMERMANN, Maria J. O. Cultura do Feijoeiro Comum no Brasil. Piracicaba: Associação Brasileira para Pesquisa da Potassa e do Fosfato, 1996.

BARBOSA, F. R.; GONZAGA, A. C. de O. (Ed.). Informações técnicas para o cultivo do feijoeiro-comum na Região Central-Brasileira: 2012-2014. Santo Antônio de Goiás: Embrapa Arroz e Feijão, 2012. 247 p. (Embrapa Arroz e Feijão. Documentos, 272).

EMBRAPA. Centro Nacional de Pesquisa de Solos. Sistema Brasileiro de Classificação de Solos. 2 ed. Rio de Janeiro: Embrapa Solos, 2006.

EMBRAPA. Centro de Pesquisa Agropecuária do Tropico Semiárido. Médias anuais da estação agrometeorológica de Bebedouro. Petrolina, 2014. Disponível em: http://www.cpatsa.embrapa.br:8080/servicos/dadosmet/ceb-anual.html. Acesso em: 19 jun. 2016.

KELLER, J.; KARMELI, D. Trickle irrigation desing. Glendora: Rain Bird Sprinkler Manufacturing, 1975.

KÖPPEN, W. Klassification der klimate nach temperatur, niederschlag und jahreslauf. Petermanns Geographische Mitteilungen, Gotha, v. 64, p. 193- 203, 1918.

REDDY, S. J.; AMORIM NETO, M. S. Dados de precipitação, evapotranspiração potencial, radiação solar global de alguns locais e classificação climática do Nordeste do Brasil. Petrolina: EMBRAPA-CPATSA, 1983. 280p.

SCOTT, A. J.; KNOTT, M. A cluster analysis method for grouping means in the analysis of variance. Biometrics, Washington, v. 30, n.2 p.507-512, 1974.

SILVA, O. F. da; WANDER, A. E. O feijão-comum no Brasil: passado, presente e futuro. Santo Antônio de Goiás: Embrapa Arroz e Feijão, 2013. 63p. (Embrapa Arroz e Feijão. Documentos, 287). 
M. Calgaro et al.

SILVEIRA, P; M da; STONE, L; F. Manejo de irrigação. IN: Agencia de Informação Embrapa Feijão. Disponível em: http://www.agencia.cnptia.embrapa.br/Agencia4/AG01/arvore/AG01_86_1311200215104.html. Acesso em 13 de novembro 2016.

Tabela 1. Coeficiente de cultura $(\mathrm{Kc})$ para as três principais fases do ciclo da cultura do feijão-comum.

\begin{tabular}{lcc}
\hline \multicolumn{1}{c}{ Fases da cultura } & $\begin{array}{c}\text { Duração da fase } \\
\text { (dias) }\end{array}$ & Kc \\
\hline Germinação até Início da floração & 35 & 0,69 \\
Floração até Início do desenvolvimento de vagens & 25 & 1,28 \\
Desenvolvimento de vagens até Maturação & 20 & 1,04 \\
\hline Fonte: Silveira e Stone 2016. &
\end{tabular}

Fonte: Silveira e Stone, 2016.

Tabela 2. Produtividades médias $\left(\mathrm{kg} \cdot \mathrm{ha}^{-1}\right)$ de linhagens de feijão-comum.

\begin{tabular}{|c|c|c|}
\hline Ordem & Nome & 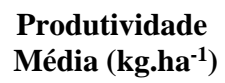 \\
\hline 1 & CNFC 15856 & $2.996,32 \mathrm{a}$ \\
\hline 2 & BRS NOTÁVEL* & $2.985,90 \mathrm{a}$ \\
\hline 3 & CNFC 16242 & $2.717,89$ a \\
\hline 4 & CNFC 16729 & $2.665,14 \mathrm{a}$ \\
\hline 5 & CNFC 15723 & $2.592,58 \mathrm{a}$ \\
\hline 6 & CNFC 16066 & $2.537,00 \quad \mathrm{a}$ \\
\hline 7 & CNFC 16871 & $2.503,18$ a \\
\hline 8 & CNFC 16831 & $2.469,96 \mathrm{a}$ \\
\hline 9 & CNFC 16832 & $2.389,54 \mathrm{a}$ \\
\hline 10 & CNFC 16188 & $2.386,68 \mathrm{a}$ \\
\hline 11 & CNFC 16846 & $2.256,51 \mathrm{~b}$ \\
\hline 12 & CNFC 16820 & $2.144,71 \quad b$ \\
\hline 13 & CNFC 15708 & $1.727,25 \quad b$ \\
\hline
\end{tabular}

Médias seguidas da mesma letra não diferem entre si pelo teste de Scott-Knott a 5\% de probabilidade. * Testemunha 